\title{
KOMPOSISI HASIL TANGKAPAN IKAN PADA ALAT TANGKAP BAGAN PERAHU KM PUSPA SARI 03 DI PERAIRAN SUMATERA BARAT
}

\section{THE EFFECT OF FISHING TIME ON FISHING RESULTS AT KM PUSPA SARI 03 IN WEST SUMATRA WATERS}

\author{
Eli Nurlaela', M. Afif Al-Magribi ${ }^{1}$, Eddy Sugriwa Husein ${ }^{1}$, Tatty Yuniarty ${ }^{1}$, Sarifah Aini ${ }^{1}$ \\ Robet Perangin-angin ${ }^{2}$, lya Purnama Sari ${ }^{3}$, Angkasa Putra ${ }^{1}$ \\ ${ }^{1}$ Politeknik Ahli Usaha Perikanan \\ JI. AUP No. 1 Pasar Minggu-Jakarta Selatan, Jakarta 12520 \\ ${ }^{2}$ Prodi Teknik Penangkapan Ikan Politeknik Kelautan dan Perikanan Karawang \\ Jl. Lingkar Tanjungpura, Karangpawitan, Kec. Karawang Bar., Kabupaten Karawang, Jawa Barat 41315 \\ ${ }^{3}$ Prodi Perikanan Tangkap Politeknik Kelautan dan Perikanan Jembrana \\ Pengambengan, Kec. Negara, Kabupaten Jembrana, Bali 82218 \\ *Email: elimumtaza@gmail.com
}

\begin{abstract}
ABSTRAK
Pelabuhan Perikanan Samudera Bungus memiliki potensi perikanan yang melimpah. Produksi hasil perikanannya semakin meningkat setiap tahunnya. Posisi Pelabuhan Perikanan Samudera Bungus juga sangat dekat dengan WPP 572. Alat tangkap yang banyak digunakan di Pelabuhan Perikanan Bungus adalah Bagan Berahu. Penelitian ini dilakukan dengan tujuan untuk mengetahui komposisi hasil tangkapan bagan perahu pada KM PUSPA SARI 03 di Perairan Sumatera Barat. Penelitian ini dilaksanakan selama 134 hari yaitu pada tanggal 11 Januari 2021 sampai dengan 25 Mei 2021 dengan melakukan operasi penangkapan ikan di perairan Sumatera Barat pada KM PUSPA SARI 03 yang berpengkalan di Pelabuhan Perikanan Samudra Bungus, Kota Padang, Sumatera Barat. Teknik pengambilan data yang digunakan yaitu observasi/pengamatan langsung di lapangan. Hasil penelitian menunjukan bahwa terdapat 3 jenis ikan hasil tangkapan utama kapal bagan perahu KM. Puspa Sari 03 yaitu: Tongkol (Euthynnus affinis), Tuna sirip Kuning (Thunnus albacares), dan Layang Deles (Decapterus macrosoma). Total hasil tangkapan sebanyak $62.674 \mathrm{~kg}$, dengan komposisi hasil tangkapan yaitu ikan tongkol sebesar $49 \%$ atau $(30.840 \mathrm{~kg})$ kemudian ikan layang deles sebesar 35 $\%$ atau $(21.690 \mathrm{~kg})$ dan ikan tuna sirip kuning sebesar $16 \%$ atau $(10.144 \mathrm{~kg})$. Data tersebut di dapat selama 14 trip penangkapan dengan jumlah setting 96 kali.
\end{abstract}

Kata Kunci: Bagan Perahu, Komposisi Hasil Tangkapan, KM. Puspa Sari 03, Sumatera Barat

\begin{abstract}
Bungus Ocean Fishing Port has abundant fisheries potential. Production of fishery products is increasing every year. The position of the Bungus Ocean Fishing Port is also very close to WPP 572. The fishing gear that is widely used at the Bungus Fishery Port is Boat Lift Net. This research was conducted with the aim of knowing the composition of the catch of the Boat Lift Net at KM PUSPA SARI 03 in the waters of West Sumatra. This research was carried out for 134 days, on January 11, 2021 to May 25, 2021 by carrying out fishing operations in the waters of West Sumatra at KM PUSPA SARI 03 which is based at the Bungus Ocean Fishing Port, Padang City, West Sumatra. The results showed that there are 3 types of fish that are the main catches of the KM Puspa Sari 03 are: Tuna (Euthynnus affinis), Yellowfin Tuna (Thunnus albacares), and Layang Deles (Decapterus macrosoma). The total catch was $62,674 \mathrm{~kg}$, with the composition of the catch, namely tuna fish by $49 \%$ or $(30,840$ $\mathrm{kg}$ ) then scad fish by $35 \%$ or $(21,690 \mathrm{~kg})$ and yellowfin tuna by $16 \%$ or $(10,144 \mathrm{~kg})$. The data can be for 14 fishing trips with a total of 96 settings.
\end{abstract}

Keywords: Boat Lift Net, Catch Composition, KM. Puspa Sari 03, West Sumatra 
Buletin JSJ, 3 (2), 2021, 53-62

Available online di: http://ejournal-balitbang.kkp.go.id/index.php/JSJ/index

\section{PENDAHULUAN}

Menurut Dinas Kelautan dan Perikanan Sumatera Barat (2011), Bappeda dan BPS Provinsi Sumatera Barat (2011) dan menurut Adry \& Putri (2018), Sumatera Barat memiliki potensi kelautan dan perikanan yang cukup besar dan sangat potensial baik perairan umum maupun perairan laut. Armada yang banyak melakukan penangkapan ikan di Pelabuhan Perikanan Samudera Bungus salah satunya yaitu alat tangkap bagan perahu yang tergolong kedalam lift net (Tamara, 2018). Menurut Lee (2010), bagan merupakan salah satu jaring angkat yang dioperasikan di perairan pantai pada malam hari dengan menggunakan cahaya lampu sebagai faktor penarik ikan. Bagan perahu ini sering pula disebut juga sebagai bagan perahu listrik. Pada tepian jaring terdapat tali ris yang berfungsi untuk menguatkan tepi jaring sehingga tidak terbelit. Setiap tepi jaring dilengkapi dengan tali yang berfungsi untuk menurunkan dan mengangkat jaring pada saat pengoperasiannya. Konstruksi alat tangkap bagan perahu ini terdiri dari jaring, bambu, pipa besi, tali temali, lampu dan kapal bermesin. Bagian jaring dari bagan ini terbuat dari bahan waring yang dibentuk menjadi kantong. Bagian kantong terdiri dari lembaran-lembaran waring yang dirangkai atau dijahit sedemikian rupa sehingga dapat membentuk kantong berbentung bujur sangkar yang dikarenakan adanya kerangka yang dibentuk oleh bambu dan pipa besi (Tamara, 2018).

Alat bantu lampu umumnya digunakan saat operasi penangkapan Bagan, dengan tujuan ikan yang menjadi target penangkapan memiliki sifat tertarik terhadap cahaya (fototaksis positif) fungsi cayaha dalam penangkapan ikan ini adalah untuk mengumpulkan ikan sampai pada suatu waktu tertentu, lalu penangkapan dilakukan dengan alat jaring ataupun pancing dan alat-alat lainnya Pemanfaatan cahaya sebagai alat bantu penangkapan sangat berkaitan dengan tingkah laku ikan terhadap cahaya. Dasarnya adalah ikan pada umumnya mencari makan dengan memanfaatkan indera pengelihatan (Nurlindah, 2018).

Pengoperasian bagan perahu di perairan Sumatera Barat mulai saat matahari terbenam sekitar pukul 18.00 sampai matahari terbitnya Matahari yakni sekitar pukul 06.00. Operasi penangkapan dengan bagan perahu ditandai dengan proses setting yakni pemasangan jaring di bingkai waring dan hauling yakni pengangkatan jaring. Proses setting terkadang dilakukan selama operasi penangkapan ikan sebanyak 1 sampai 2 kali, tergantung ada dan tidaknya ikan yang berkumpul di lokasi penangkapan. Pada saat musim puncak ketika jumlah ikan banyak maka dalam semalam dapat dilakukan setting dan hauling sebanyak 3 kali. Namun saat musim paceklik setting dan hauling dilakukan sebanyak 1 kali bahkan sama sekali tidak melakukan setting. Proses hauling dimulai dengan pengamatan terhadap gerombolan ikan yang berada di area penangkapan. Apabila kawanan ikan sudah terlihat, maka dilakukan pemadaman lampu satu per satu. Hal tersebut dimaksudkan agar ikan terkumpul pada bagian tengah jarring (cathable area). Pemadaman lampu juga diilakukan secara bertahap, mulai daribagian luar/sisi kapal dan selanjutnya pada bagian tengah kapal. Selanjutnya lampu dipadamkan semua dan dimulai dengan penurunan waring sampai dengan penarikan waring dengan menggunakan alat bantu roller. Baskoro et al. (2004) mengemukakan bahwa hasil tangkapan bagan perahu setelah waktu tengah malam lebih besar dibandingkan pengoperasian sebelum waktu tengah malam. Hal ini disebabkan sedikitnya oleh 2 hal yaitu sifat fototaksis dan feeding behavior. Pada kondisi setelah tengah malam, kehadiran cahaya lampu petromak cenderung memberikan daya tarik yang lebih besar karena kondisi perairan yang lebih gelap. Ikan yang berfototaksis positif akan lebih cepat dan banyak berkumpul disekitar bagan. Selain itu, sifat biologis ikan tertentu yang memiliki waktu mencari makan pada waktu setelah tengah malam diduga ikut berpengaruh terhadap hasil tangkapan yang diperoleh.

Berdasarkan latar belakang tersebut, penelitian ini dilakukan dengan tujuan untuk mengetahui komposisi hasil tangkapan bagan perahu pada KM PUSPA SARI 03 di Perairan Sumatera Barat. 
Buletin JSJ, 3 (2), 2021, 53-62

Available online di: http://ejournal-balitbang.kkp.go.id/index.php/JSJ/index

\section{BAHAN DAN METODE}

Bahan yang digunakan dalam kegiatan praktik akhir ini meliputi Hasil tangkapan bagan perahu KM. PUSPA SARI 03. Penelitian ini dilaksanakan selama 4 bulan (134 hari), mulai dari tanggal 11 Januari 2021 sampai dengan 25 Mei 2021 dengan melakukan operasi penangkapan ikan di perairan WPP 572 menggunakan KM PUSPA SARI 03 yang berpangkalan di Pelabuhan Perikanan Samudera Bungus, Kota Padang, Sumatera Barat.

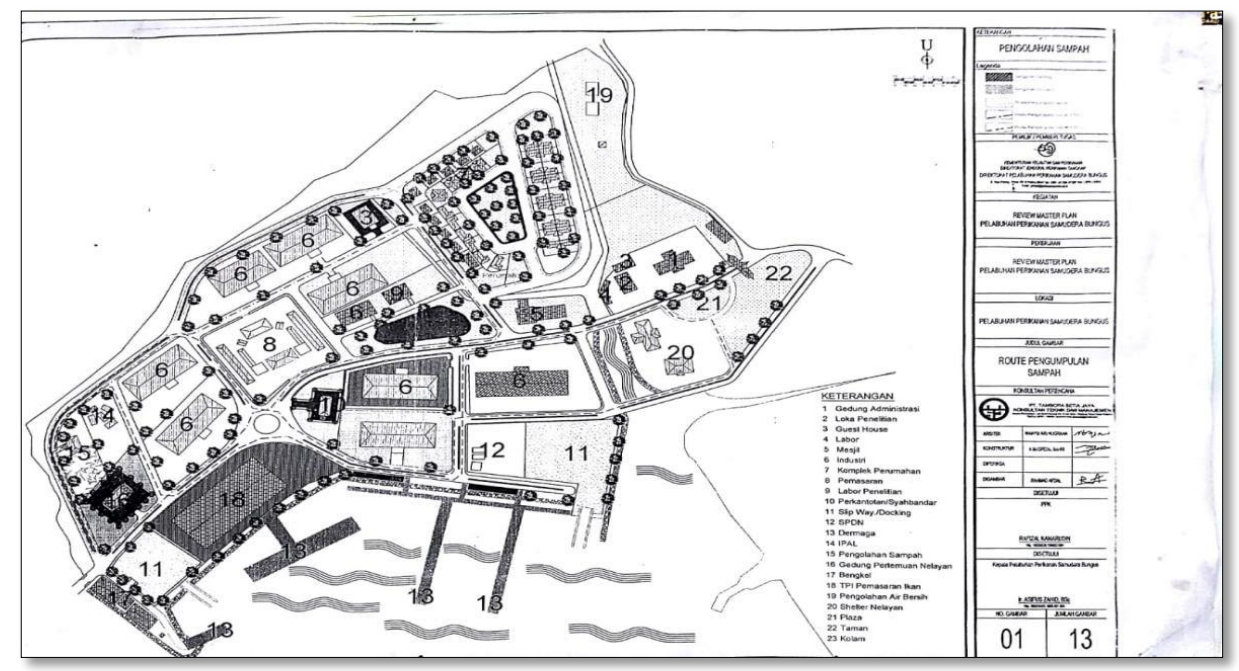

Gambar 1. Lokasi penelitian

Metode yang digunakan dalam penelitian ini adalah metode survei secara langsung, yaitu dengan melakukan pengamatan atau observasi di lapangan. Data yang di kumpulkan berupa data primer dan data sekunder. Data primer diperoleh dengan melakukan pengamatan langsung diatas kapal dengan mengikuti kegiatan operasi penangkapan ikan di kapal, data tersebut meliputi: posisi

daerah penangkapan ikan, serta jenis dan jumlah hasil tangkapan per trip data hasil tangkapan kapal

yang didaratkan di pelabuhan.

Metode survey merupakan salah satu metode penelitian noneksperimental yang paling popular (Hasanah et al, 2012). Hasil tangkapan diklasifikasikan menurut jenisnya kemudian dilakukan penimbangan untuk setiap jenis ikan selanjutnya hasil tangkapan dikelompokkan ke dalam tabel tangkapan untuk setiap unit penangkapan bagan perahu. Data tersebut, baik jumlah, komposisi hasil tangkapan dan lainnya disajikan dalam bentuk tabel dan gambar. Menurut Komposisi jenis ikan hasil tangkapan dapat dihitung dengan persamaan sebagai berikut :

Keterangan :

$$
p i=\frac{n i}{N} \times 100 \%
$$

$\mathrm{Pi}=$ Kelimpahan Hasil Tangkapan (\%)

$\mathrm{ni}=$ Jumlah Hasil Tangkapan Spesies $(\mathrm{kg})$

$\mathrm{N}=$ Jumlah Total Hasil Tangkapan $(\mathrm{kg})$

\section{HASIL DAN PEMBAHASAN}

\section{Daerah Penangkapan Ikan}

Daerah Penangkapan Ikan merupakan aspek yang sangat penting dalam kegiatan penangkapan ikan. Untuk operasi penangkapan yang bersifat komersial diperlukan 
Available online di: http://ejournal-balitbang.kkp.go.id/index.php/JSJ/index

pengetahuan tentang daerah penangkapan ikan. Pengetahuan ini sangat berguna dalam menghadapi musim-musim paceklik (Sudirman, 2015). Daerah Penangkapan Ikan merupakan aspek yang sangat penting dalam kegiatan penangkapan ikan. KM. PUSPA SARI 03 melakukan kegiatan penangkapan ikan pada rumpon yang sudah di tanam oleh kapal yang kemudian menjadi daerah penangkapan oleh masyarakat setempat. KM PUSPA SARI 03 memiliki beberapa rumpon yang berada di perairan pulau gosong dengan posisi Lintang $01^{\circ} 09^{\prime} 361^{\prime \prime}$ LU dan Bujur $100^{\circ} 08^{\prime} 453^{\prime \prime}$ BT dan di perairan Mentawai dengan posisi

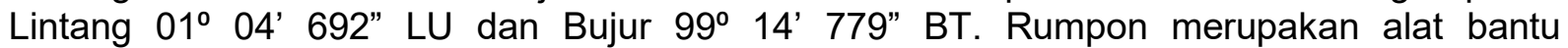
penangkap ikan yang berfungsi untuk menarik kelompok ikan agar berkumpul di sekitarnya (Nurdin et al, 2012).

Daerah penangkapan ikan pada KM PUSPA SARI 03 dapat dilihat pada tabel 1.

Tabel 1. Daerah Penangkapan dan Titik Rumpon

\begin{tabular}{|c|c|c|c|}
\hline No & Lintang & Bujur & Nama Rumpon \\
\hline 1 & $01^{\circ} 18^{\prime} 36^{\prime \prime}$ LS & $100^{\circ} 18^{\prime} 36^{\prime \prime} \mathrm{BT}$ & Rumpon Pokai \\
\hline 2 & $01^{\circ} 24^{\prime} 57^{\prime \prime}$ LS & $99^{\circ} 25^{\prime} 20^{\prime \prime} \mathrm{BT}$ & Gosong Laut \\
\hline 3 & $01^{\circ} 03^{\prime} 58^{\prime \prime}$ LS & $99^{\circ} 57^{\prime} 54^{\prime \prime}$ BT & Rumpon popy 01 \\
\hline 4 & $01^{\circ} 13^{\prime} 19^{\prime \prime}$ LS & $99^{\circ} 32^{\prime} 97^{\prime \prime}$ BT & Rumpon Slberut \\
\hline 5 & $01^{\circ} 21^{\prime} 22^{\prime \prime}$ LS & $99^{\circ} 33^{\prime} 26^{\prime \prime}$ BT & Pulau Nyamuk \\
\hline 6 & $01^{\circ} 19^{\prime} 37^{\prime \prime}$ LS & $100^{\circ} 6^{\prime} 17^{\prime \prime} \mathrm{BT}$ & Rumpon Diah 010 \\
\hline 7 & $01^{\circ} 02^{\prime} 367^{\prime \prime}$ LS & $99^{\circ} 94^{\prime} 179^{\prime \prime}$ ВТ & Rumpon Tuapejat \\
\hline 8 & $01^{\circ} 02^{\prime} 367^{\prime \prime}$ LS & $99^{\circ} 14^{\prime} 279^{\prime \prime}$ ВT & Pulau Sikabaluan \\
\hline 9 & $01^{\circ} 09^{\prime} 361^{\prime \prime} \mathrm{LU}$ & $100^{\circ} 08^{\prime} 453^{\prime \prime} \mathrm{BT}$ & Rumpon Anak rantai \\
\hline 10 & $01^{\circ} 09^{\prime} 361^{\prime \prime}$ LS & $99^{\circ} 14^{\prime} 779^{\prime \prime}$ ВТ & Rumpon pasang laut \\
\hline 11 & $01^{\circ} 13^{\prime} 19^{\prime \prime} \mathrm{LS}$ & $99^{\circ} 13^{\prime} 19^{\prime \prime} \mathrm{BT}$ & Rumpon Kasang \\
\hline
\end{tabular}

\section{Komposisi Hasil Tangkapan Selama Penelitian}

Kegiatan operasi penangkapan ikan dengan bagan perahu pada KM. Puspa Sari 03 dilakukan pada WPP 572 di sekitaran perairan Mentawai dengan fishing ground yang berbeda beda yang dimana pada fishing ground tersebut terdapat rumpon - rumpon yang sudah ditandai lokasi koordinatnya menggunakan GPS. Adapun jenis hasil tangkapan selama penelitian sebagai berikut: 
Buletin JSJ, 3 (2), 2021, 53-62

Available online di: http://ejournal-balitbang.kkp.go.id/index.php/JSJ/index

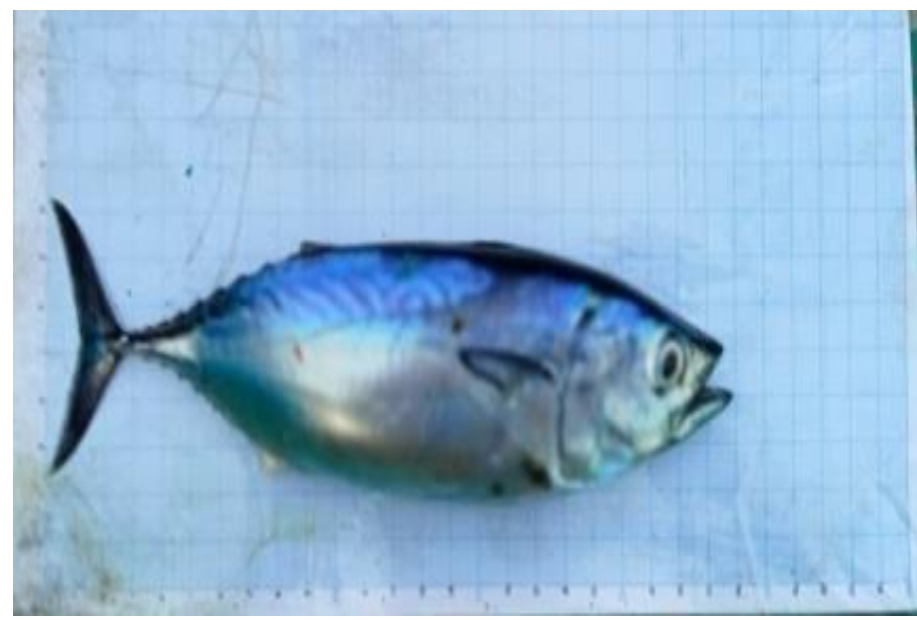

Gambar 2. Ikan Tongkol (Euthynnus affinis).

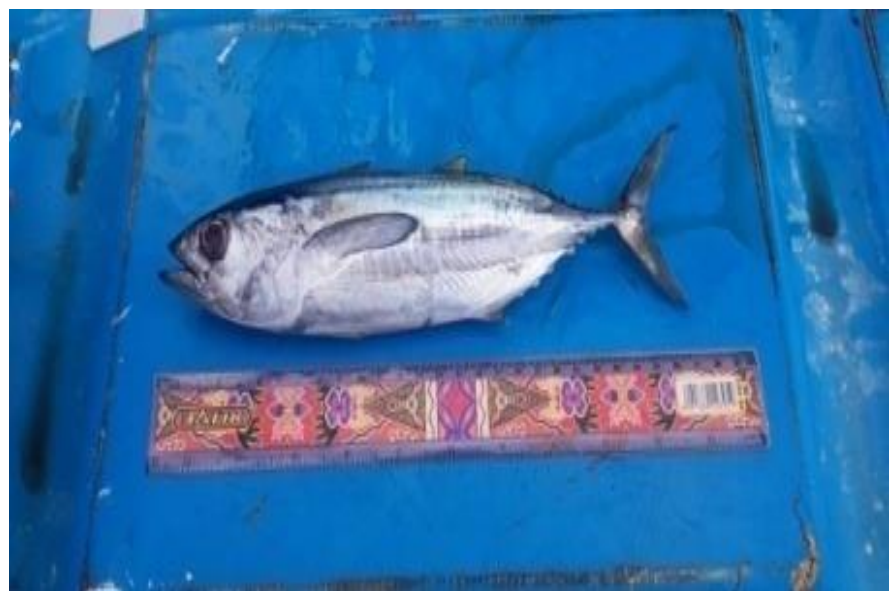

Gambar 3. Tuna Sirip Kuning (Thunnus albacares).

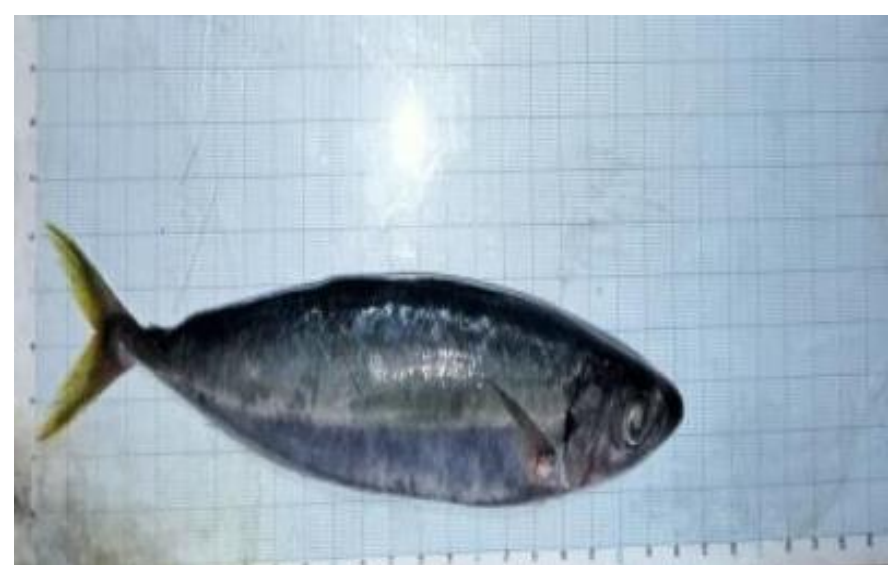

Gambar 4. Layang Deles (Decapterus macrosoma).

Komposisi Hasil Tangkapan Pada Bulan Januari 2021

Jenis hasil tangkpan yang didapatkan pada saat pengoperasian pada bulan Januari 2021 dapat di lihat pada tabel berikut. 
Buletin JSJ, 3 (2), 2021, 53-62

Available online di: http://ejournal-balitbang.kkp.go.id/index.php/JSJ/index

Tabel 2. Hasil tangkapan bulan Januari 2021

\begin{tabular}{clcc}
\hline No & \multicolumn{1}{c}{ Nama lkan } & Jumlah $(\mathrm{kg})$ & $\begin{array}{c}\text { Komposisi } \\
\text { Tangkapan }(\%)\end{array}$ \\
\hline 1 & Tongkol & 6.900 & 54 \\
2 & Tuna Sirip Kuning & 2.410 & 19 \\
3 & Layang Deles & 3.435 & 27 \\
\hline \multicolumn{2}{c}{ Jumlah } & 12.745 & 100 \\
\hline
\end{tabular}

Berdasarkan tabel diatas, jumlah jenis hasil tangkapan yang diperoleh pada bulan Januari 2021 yaitu ikan Tongkol sebanyak $6.900 \mathrm{~kg}$ (54\%), Tuna sirip kuning sebanyak $2.410 \mathrm{~kg}$ (19\%) dan Tuna Layang deles sebanyak $3.435 \mathrm{~kg}$ (27\%). Jadi seluruh jumlah hasil tangkapan yang didapatkan selama bulan Januari 2021 adalah sebanyak $12.745 \mathrm{~kg}$. Diagram komposisi hasil tangkapan bulan Januari dapat dilihat pada gambar di bawah.

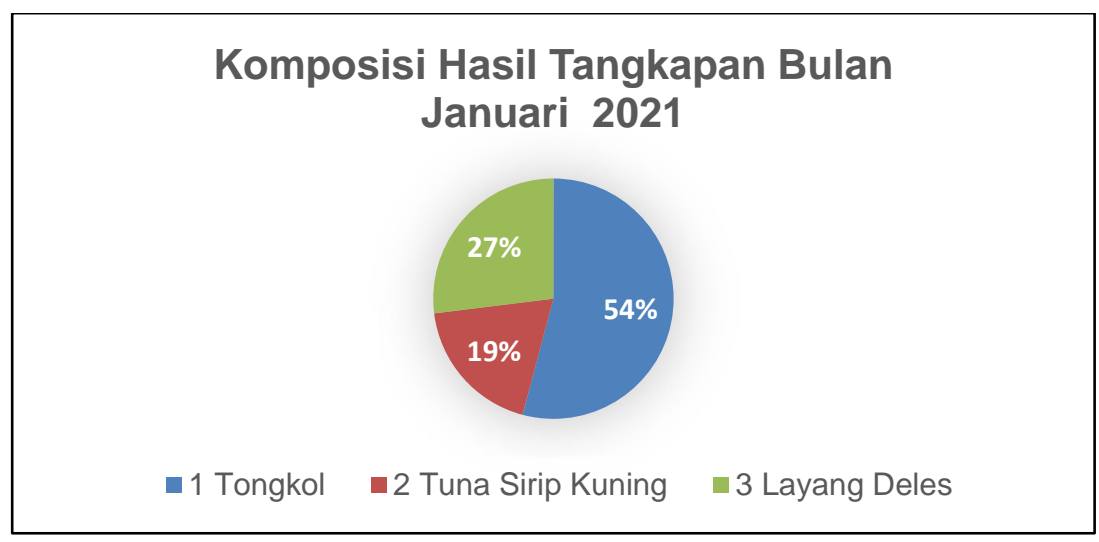

Gambar 5. Komposisi Hasil Tangkapan Bulan Januari 2021.

Berdasarkan diagram diatas dapat diuraikan bahwa hasil tangkapan pada bulan Januari 2021 terdiri dari ikan Tongkol sebesar 54\%, Tuna sirip kuning sebesar 19\%, Layang Deles sebesar 27\%. Hasil ini diperoleh dari 18 kali setting dan 3 trip operasional penangkapan ikan.

\section{Komposisi Hasil Tangkapan Pada Bulan Februari 2021}

Jenis hasil tangkapan yang didapatkan pada saat operasi penangkapan pada bulan Februari 2021 dapat dilihat pada tabel di bawah ini.

Tabel 3. Hasil tangkapan pada bulan Februari 2021

\begin{tabular}{clcc}
\hline No & \multicolumn{1}{c}{ Nama lkan } & Jumlah $(\mathrm{kg})$ & Komposisi Tangkapan (\%) \\
\hline 1 & Tongkol & 13.035 & 57 \\
2 & Tuna Sirip Kuning & 2.944 & 13 \\
3 & Layang Deles & 7.035 & 30 \\
\hline & Jumlah & 23.014 & 100 \\
\hline
\end{tabular}

Berdasarkan tabel di atas jumlah jenis hasil tangkapan yang diperoleh pada bulan Februari 2021 yaitu Tongkol sebanyak $13.035 \mathrm{~kg}$ (57\%), Tuna sirip kuning sebanyak $2.944 \mathrm{~kg}(13 \%)$, dan Layang Deles sebanyak $7.035 \mathrm{~kg}(30 \%)$. Adapun persentase hasil tangkapan bulan Februari 2021 dapat dilihat pada gambar di bawah ini. 
Buletin JSJ, 3 (2), 2021, 53-62

Available online di: http://ejournal-balitbang.kkp.go.id/index.php/JSJ/index

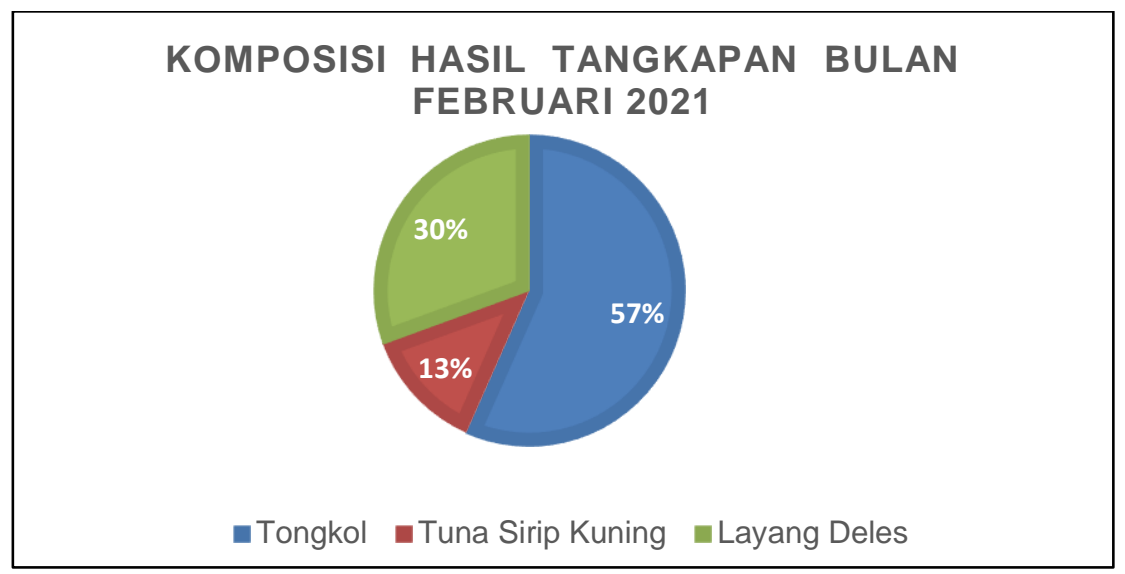

Gambar 6. Komposisi Hasil Tangkapan Bulan Februari 2021.

Berdasarkan diagram diatas dapat diuraikan bahwa hasil tangkapan pada bulan Februari 2021 terdiri dari ikan Tongkol sebesar 57\%, Tuna sirip kuning sebsar 13\%, dan Layang Deles sebesar 30\%. Hasil ini diperoleh dari 26 kali setting dan 5 trip operasional penangkapan ikan.

\section{Komposisi Hasil Tangkapan Pada Bulan Maret 2021}

Jenis hasil tangkapan yang didapatkan pada saat operasi penangkapan pada bulan April 2021 dapat dilihat pada tabel di bawah ini.

Tabel 4. Hasil tangkapan pada bulan Maret 2021

\begin{tabular}{cccc}
\hline No & Nama Ikan & Jumlah $(\mathrm{kg})$ & Komposisi Tangkapan (\%) \\
\hline 1 & Tongkol & 6.030 & 44 \\
2 & Tuna Sirip Kuning & 2.640 & 19 \\
3 & Layang Deles & 5.130 & 37 \\
\hline & & 13.800 & 100 \\
\hline
\end{tabular}

Berdasarkan tabel di atas jumlah jenis hasil tangkapan yang diperoleh pada bulan Maret 2021 yaitu Tongkol sebanyak $6.030 \mathrm{~kg}(44 \%)$, Tuna sirip kuning sebanyak $2.640 \mathrm{~kg}(19 \%)$ dan Layang Deles sebanyak $5.130 \mathrm{~kg}(37 \%)$. Jadi seluruh jumlah hasil tangkapan yang didapatkan selama bulan Maret 2021 adalah sebanyak $13.800 \mathrm{~kg}$. Adapun persentase hasil tangkapan bulan April 2021 dapat dilihat pada gambar di bawah ini.

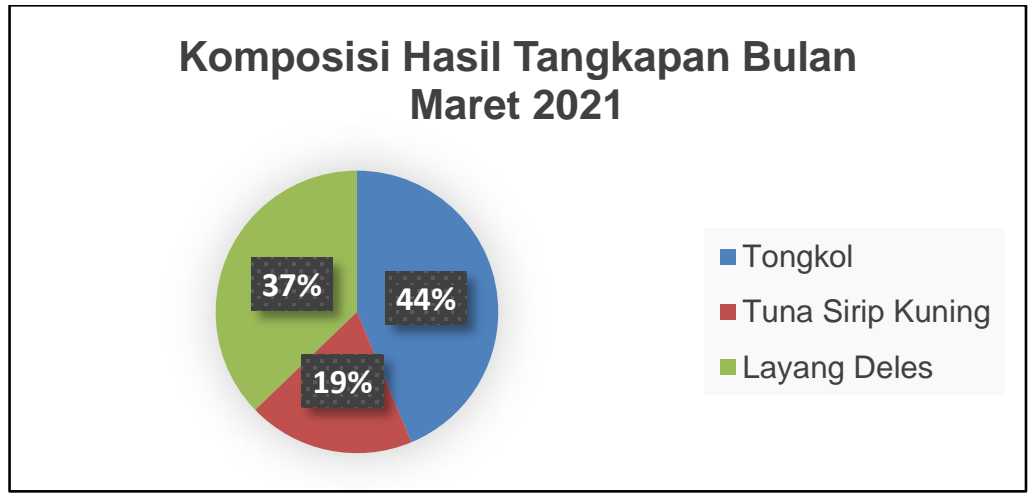

Gambar 6. Komposisi Hasil Tangkapan Bulan Maret 2021. 
Berdasarkan diagram diatas dapat diuraikan bahwa hasil tangkapan pada bulan Maret 2021 terdiri dari ikan Tongkol sebesar 44\%, Tuna sirip kuning sebanyak sebesar 19\%, dan Layang Deles sebesar $37 \%$. Hasil ini diperoleh dari 28 kali setting dan 3 trip operasional penangkapan ikan.

\section{Komposisi Hasil Tangkapan Pada Bulan April 2021}

Jenis hasil tangkapan yang didapatkan pada saat operasi penangkapan pada bulan April 2021 dapat dilihat pada tabel di bawah ini.

Tabel 5. Hasil tangkapan pada bulan April 2021

\begin{tabular}{clcc}
\hline No & \multicolumn{1}{c}{ Jenis lkan } & Jumlah $(\mathrm{kg})$ & Komposisi Tangkapan $(\%)$ \\
\hline 1 & Tongkol & 4.875 & 37 \\
2 & Tuna Sirip Kuning & 2.150 & 16 \\
3 & Layang Deles & 6.090 & 47 \\
\hline & & 13.115 & 100 \\
\hline
\end{tabular}

Berdasarkan tabel di atas jumlah jenis hasil tangkapan yang diperoleh pada bulan April 2021 yaitu Tongkol sebanyak $4.875 \mathrm{~kg}$ (37\%), Tuna sirip kuning sebanyak $2.150 \mathrm{~kg}$ (16\%), dan Layang Deles sebanyak $6.090 \mathrm{~kg}(47 \%)$. Jadi seluruh jumlah hasil tangkapan yang didapatkan selama bulan April 2021 adalah sebanyak $13.115 \mathrm{~kg}$. Adapun persentase hasil tangkapan bulan April 2021 dapat dilihat pada gambar berikut.

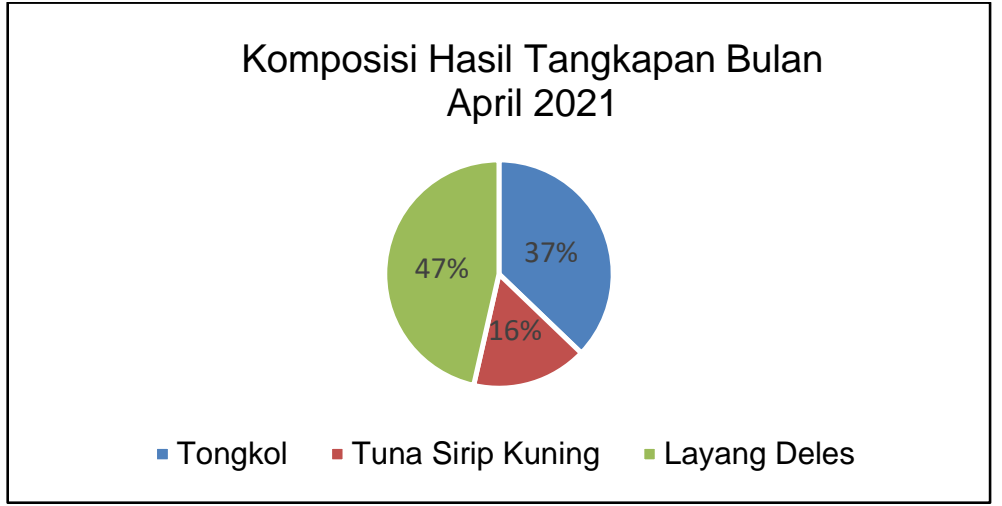

Gambar 7. Komposisi Hasil Tangkapan April 2021.

Berdasarkan diagram diatas dapat diuraikan bahwa hasil tangkapan pada bulan April 2021 terdiri dari ikan Tongkol sebesar 37\%, Tuna sirip kuning sebesar 16\%, dan Layang Deles sebesar $47 \%$. Hasil ini diperoleh dari 28 kali setting dan 3 trip operasional penangkapan ikan.

\section{Persentase Hasil Tangkapan Selama 4 Bulan}

Komposisi hasil tangkapan yang didapatkan pada KM PUSPA SARI 03 selama empat bulan, yakni dari Januari 2021 - April 2021 diperoleh hasil sebagai berikut, pada bulan Januari 2021 hasil tangkapan yang diperoleh sebanyak $12.745 \mathrm{~kg}$ dengan jumlah setting $18 \mathrm{kali}$ setting dalam 3 trip, pada bulan Februari hasil tangkapan yang diperoleh sebanyak 23.014 $\mathrm{kg}$ dengan jumlah 26 kali setting dalam 5 trip, pada bulan Maret 2021 hasil tangkapan yang diperoleh sebanyak 13. $800 \mathrm{~kg}$ dengan jumlah 28 kali setting dalam 3 trip dan hasil tangkapan yang didapatkan pada bulan April 2021 sebanyak $13.115 \mathrm{~kg}$ dengan jumlah 28 kali setting dalam 3 trip. Sehingga dapat diambil kesimpulan dari pernyataan di atas bahwa 
Buletin JSJ, 3 (2), 2021, 53-62

Available online di: http://ejournal-balitbang.kkp.go.id/index.php/JSJ/index

hasil tangkapan yang diperoleh selama empat bulan yakni, bulan Januari 2021 sampai dengan April 2021 sebanyak 62.574 kg sebanyak 96 kali setting dalam 14 trip. Hasil tangkapan selama 4 bulan dapat dilihat pada tabel di bawah ini.

Tabel 6. Hasil Tangkapan KM. Puspa Sari 03 Selama 4 Bulan

\begin{tabular}{clccc}
\hline No & Bulan & Setting & Trip & Persentase (\%) \\
\hline 1 & Januari & 18 & 3 & 20 \\
2 & Februari & 26 & 5 & 37 \\
3 & Maret & 28 & 3 & 22 \\
4 & April & 28 & 3 & 21 \\
\hline \multicolumn{2}{r}{ Total } & 96 & 14 & 100 \\
\hline
\end{tabular}

Berdasarkan tabel diatas bahwa hasil tangkapan selama empat bulan diatas yakni pada bulan Januari 2021 sebanyak 20\%, Februari 2021 sebanyak 37\%, Maret 2021 sebanyak $22 \%$, dan April 2021 sebanyak 21\%. Sehingga dapat diambil kesimpulan bahwa hasil tangkapan yang paling tertinggi pada bulan Februari 2021 dengan persentase $37 \%$ dan hasil tangkapan yang terendah terdapat pada bulan Januari 2021 dengan persentase $20 \%$.

\section{Komposisi Hasil Tangkapan Keseluruhan Selama Penelitian}

Komposisi hasil tangkapan selama penelitian kurang lebih 4 bulan di KM PUSPA SARI 03, selama 14 trip penangkapan dan jumlah setting 96 kali, diperoleh hasil sebagai berikut :

Tabel 7. Komposisi Hasil Tangkapan Selama Penelitian

\begin{tabular}{clcc}
\hline No & \multicolumn{1}{c}{ Ikan Hasil Tangkapan } & $\begin{array}{c}\text { Jumlah Hasil } \\
\text { Tangkapan (kg) }\end{array}$ & $\begin{array}{c}\text { Komposisi Jenis Hasil } \\
\text { Tangkapan (\%) }\end{array}$ \\
\hline 1 & $\begin{array}{l}\text { Tongkol } \\
\text { (Euthynnus affinis) }\end{array}$ & 30.840 & 49 \\
2 & $\begin{array}{l}\text { Tuna Sirip Kuning (Thunnus } \\
\text { albacares) } \\
3\end{array}$ & 10.144 & 16 \\
Layang Deles & (Decapterus macrosoma) & 21.690 & 35 \\
\hline \multicolumn{1}{c}{ Jumlah } & 62.674 & 100 \\
\hline
\end{tabular}

\section{KESIMPULAN DAN SARAN}

\section{Kesimpulan}

Komposisi hasil tangkapan keseluruhan selama melakukan penelitian di KM PUSPA SARI 03 sebanyak $62.674 \mathrm{~kg}$, terlihat bahwa jenis ikan yang paling dominan tertangkap pada bagan perahu adalah Ikan Tongkol sebesar $30.840 \mathrm{~kg}(49 \%)$, Layang Deles sebesar 21.690 (35\%), dan Tuna sirip kuning sebesar 10.144 (16\%). Sehingga dapat disimpulkan bahwa jenis ikan yang paling banyak tertangkap selama melakukan penelitian adalah ikan Tongkol dengan Presentase $49 \%$ dan ikan paling sedikit tertangkap adalah ikan tuna sirip kuning dengan presentase $16 \%$.

\section{Saran}

Pentingnya adanya teknologi canggih atau pembaruan terhadap mesin Roller dengan tujuan untuk penarikan jaring lebih efisien waktu sehingga resiko ikan keluar dari jaring dapat diminimalisir agar hasil tangkapan yang didapat lebih maksimal. 
Buletin JSJ, 3 (2), 2021, 53-62

Available online di: http://ejournal-balitbang.kkp.go.id/index.php/JSJ/index

\section{DAFTAR PUSTAKA}

Bappeda dan BPS Provinsi Sumatera Barat. (2011). Sumatera Barat Dalam Angka Tahun 2011. Kerjasama Badan Perencanaan Pembangunan Daerah Provinsi Sumatera Barat dan Badan Pusat Statistik Sumatera Barat. Padang.

Baskoro. (2004). Pengaruh Intensitas Cahaya Dan Lama Waktu Pencahayaan Terhadap Adaptasi Retina Ikan Tembang. Buletin PSP.134-47.

Dinas Kelautan dan Perikanan (DKP). (2011). Profil Perikanan Tangkap Provinsi Sumatera Barat.

Hasanah, Mustari, Muhamad., \& Rahman, M.T. (2012). Pengantar Metode Penelitian. Laksbang Pressindo, Yogyakarta. ISBN 9789792685626.

Lee, J.W. (2010). Pengaruh Periode Hari Bulan Terhadap Hasil Tnagkapan Dan Tingkat Pendapatan Nelayan Bagan Tancap di Kabupaten Serang. Institut Pertanian Bogor. Bogor. 100.

Adry, M.R. \& Putri, D.Z. (2018). Analisis Kajian Potensi Sumberdaya Perairan dalam Pengembangan Ekonomi Wilayah Berbasis Perikanan Laut di Provinsi Sumatera Barat. Institute Pertanian Bogor.

Nurdin E., Taurusman., \& Yusfiandayani, R. (2012). Optimasi Jumlah Rumpon, Unit Armada Dan Musim Penangkapan Perikanan Tuna Di Perairan Prigi, Jawa Timur. Jurnal Penelitian Perikanan Indonesia, 18 (1), 53-60.

Nurlindah, A, Kurnia, M., \& Nelwan, A.F (2018) Perbedaan produksi bagan perahu berdasarkan periode bulan di perairan kabupaten baru. Jurnal IPTEKS PSP, 4(8), 120127.

Sudirman. (2015). Mengenal Alat Dan Metode Penangkapan Ikan. Rineka Cipta Makassar.

Tamara, R. (2018). Produktivitas Perikanan Tangkap Bagan Perahu Di Pelabuhan Perikanan Samudera Bungus Provinsi Sumatera Barat. Jurnal Online Mahasiswa Fakultas Perikanan dan IImu Kelautan Universitas Riau. 5(2), 1-13. 